\section{Renewing models for change}

\author{
Johanna E. Pregmark \\ Department of Technology Management and Economics, Chalmers University of \\ Technology, Gothenburg, Sweden; Center for Higher Ambition Leadership Europe, \\ Gothenburg, Sweden and Foundation IMIT, Gothenburg, Sweden
}

Renewing models for change

\begin{abstract}
Purpose - This paper aims to contribute to discussion around the need for improved models for change in a rapidly changing world. It also aims to provide insights for further discussion around how a Nordic management approach can relate to the need for new change ideas. Since Lewin proposed that change requires unfreezing, moving and refreezing, several changes in models have been introduced. Many models include similar factors such as the need for a vision, a clear process and to motivate change. These change factors are investigated in this paper and related to a fast-paced, uncertain and volatile environment

Design/methodology/approach - Based on a collaborative research approach, engaging with leaders in five organizations, all headquartered in the Nordic countries, this paper examines problems with traditional change models in a contemporary context as well as how these challenges could be handled.

Findings - This paper concludes that leaders still find value in traditional models but see that these models need to be adapted to include elements of more recent research. This paper suggests tweaks in traditional change factors and ends with a proposition with a renewed model for change.

Originality/value - The ideas in this paper could be seen as a bridge between traditional and modern models - a bridge that seems to be needed in practice. It draws on action research and close relationships with top management, as they are working with change - potentially giving the study a unique angle on a practical, widespread problem: succeeding with change
\end{abstract}

Keywords Gender, Diversity, Androgyny, Leader prototypes, Political leadership, Change models, Change formula, Contemporary context, Action research

Paper type Research paper

\section{Introduction}

The following scene played out in Newsgroup, a media group struggling to cope with digitalization in a rapidly changing environment.

Like a mantra, the top management team of Newsgroup, kept repeating that 'Everything that could be done jointly should be done jointly.' The idea was to create direction, clarity, and a sense of urgency that would guide the change initiatives ahead. When asked if they thought this message would inspire the organization to mobilize towards the future, the editor-in-chief said: 'It

(C) Johanna E. Pregmark. Published by Emerald Publishing Limited. This article is published under the Creative Commons Attribution (CC BY 4.0) licence. Anyone may reproduce, distribute, translate and create derivative works of this article (for both commercial and non-commercial purposes), subject to full attribution to the original publication and authors. The full terms of this licence maybe seen at http://creativecommons.org/licences/by/4.0/legalcode

The author grateful to the leaders in the investigated organizations for partaking in this research endeavor. Further, she thanks her colleagues in the Center for Higher Ambition Leadership, Europe and the USA, especially Tobias Fredberg, Björn Frössevi, Magnus Finnström, Flemming Norrgren and Sean Quigley, for their contributions and support in the development of these ideas. She also thanks the guest editors Ulrik Brand and Jonas Sprogoe along with the great anonymous reviewers for their engagement with her work.
Received 28 June 2021 Revised 7 October 2021 Accepted 27 January 2022

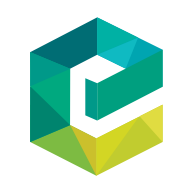

The Learning Organization Vol. 29 No. 3, 2022 Emerald Publishing Limited 0969-6474 DOI 10.1108/TLO-05-2021-0056 
TLO

29,3

is not inspiring at all. I would love to provide more hope to the organization through an aspirational vision - it"s just that I don"t know what the future will look like.

The scene above is taken from a learning journal for a collaborative research project, back in 2015 , and the quote from the editor-in-chief was a response to a question posted by the research team when participating in a top management meeting. It illustrates one aspect of how traditional models for change can be problematic. While many change models state the need for top management to devise a clear vision (Senge, 1990; Beer, 2009; Beckhard and Harris, 1987; Gill, 2003), in Newsgroup's case, that simply was not possible. Neither the top management team (TMT), nor the whole media industry, had a clear idea of what the future business would look like. Moreover, although the top management successfully communicated the urgency of change - which is advised in many change models (Kotter, 2008; Beckhard and Harris, 1987) it did not seem to energize the organization to create the future.

This paper draws upon a collaborative research approach, with different forms of interactions with leaders in five organizations undergoing change journeys to adapt to a fastmoving environment. All investigated organizations are head-quartered in one of the Nordic countries. Previous research has characterized Nordic based organizations and management with elements, such as lower power distance (Hofstede, 1980), flat organizations (Hofstede, 1980; Czarniawska-Joerges and Sevón, 2003) - characteristics that could influence the ability for an organization to change successfully (Aiginger and Guger, 2006).

Data points toward that older methods and models for working with major change have challenges in a context, where the future is uncertain, and the magnitude of the required changes is greater. Many leaders in this study see the need for less hierarchical approaches (Bartunek and Woodman, 2014; Lee and Edmondson, 2017) and for agile processes (Winby and Worley, 2014; Ancona, Backman and Isaacs, 2019) characterized by learning (Senge, 1990; Edmondson, 2019; Ortenblad, 2002) than often described in traditional change models. Thus, this study uncovers challenges of applying traditional models in a modern context, where the future is difficult to predict, and the journey ahead can be hard to detail and map out from the top. However, the strengths of traditional models are also discussed as well as how leaders adjust the meaning of the models to a new context. In this paper, I therefore suggest what seems to be beneficial to keep in existing models but potentially needs to be reinterpreted. I discuss how components can mirror traditional change models but with a strengthened role of purpose, progress, trust and positive emotions for enhanced capabilities to change. Furthermore, this study shows how leaders seem to incorporate ideas from newer thinking (Edmondson, 2019; Pasmore, 2015) into the frames of more traditional models (Kotter, 1995; Beckhard and Harris, 1987). This could potentially fill a gap between newer ideas and models for change (Bartunek and Woodman, 2014; Worley and Mohrman, 2016; Edmondson, 2019) focusing on innovation, agility and entrepreneurship (but potentially downplaying for example efficiency and need for direction) and older models focusing on direction, process and resistance (but potentially downplaying for example innovation and creativity). Thus, this paper offers a bridge between older and newer models that can make way for organizations to gradually renew their models for change at a pace fit for practitioners of change.

Next, a theoretical point of departure is outlined - focusing on the elements/factors of many traditional models - in this context understood as models to a large extent originating from Lewin's thinking in the middle of the 20th century (Rosenbaum et al., 2018), where change often is seen as a top-down controlled process between two models/states, and where the challenge is to convince/support the organization to make this shift. Thereafter, I describe the method, followed by findings regarding the change factors and its applicability and discussion, where I offer ideas of a renewed change formula - building strongly on the 
older ones but with tweaks to better fit a modern world. Each of the sectors theoretical point of departure, findings and discussion are structured around four reoccurring change factors. In the findings section, these factors are related to the data. In the discussion section, the findings about the change factors and previous knowledge are intertwined to build a foundation for my conclusions and contributions.

\section{Theoretical point of departure}

The aim of this section is to give an understanding of traditional models and common factors appearing in those. For outlining the traditional factors, the elements of the Gleicher change formula are used as a structure. These elements (strong vision, clear process, dissatisfaction and costs of change) can be seen also in many other models (Pregmark, 2019) and are therefore used as a guide through this section. In the section for theoretical point of departure, I also briefly outline characteristics of a current, contemporary context and relevant for conducting change.

\section{Traditional models for change}

In Lewin's (1947) famous three-step model, the main steps include unfreezing the current state to be able to move and refreeze in a future state. According to Bartunek and Woodman (2014) and Rosenbaum et al. (2018), little has happened with change models since. Several authors suggest that management should devise a strong vision of a future state (Senge, 1990; Gill, 2003; Kotter, 1995), whereas another common theme is the need for a process to facilitate movement (Beckhard and Harris, 1987; Armenakis and Bedeian, 1999) and to create a sense of urgency for "unfreezing" (Kotter, 2008; Beckhard and Harris, 1987). Though resistance to change has been discussed for decades, the human/relational side of the change process is a more common in newer models (Cady et al., 2014; Kotter, 1995). Rosenbaum et al. (2018) even argue that this addition has been the major contribution since Lewin (1947), perhaps connected to the increased focus on dialogic approaches to change (Bushe and Marshak, 2009).

One common proposition of how to manage change is the change formula. The first version of this formula was developed in the 1960s by David Gleicher, a consultant at Arthur D. Little (Cady et al., 2014). It was later developed in several iterations (Dannemiller and Jacobs, 1992; Beckhard and Harris, 1987; Cady et al.,0.2014). The formula outlines four clear elements that are important to manage for change to succeed; the combined effect of a strong vision, a clear process and dissatisfaction with the current state needs to exceed the perceived costs of change (both emotional and relational). Many authors emphasize vision, process, urgency and resistance/fear (Kotter, 1995; Hayes, 2018; Taffinder, 1998), though using different wordings (Armenakis and Bedeian, 1999; Rosenbaum et al., 2018). Pregmark (2019) has noted that the four elements are represented in change models from for instance Kotter (2008), Bullock and Batten (1985); Bridges (2009); and Taffinder (1998). The theoretical frame of this paper will adopt these factors/elements as a guide through the literature, exploring them one at the time.

\section{A strong vision}

The need for a vision when pursuing a change agenda is almost univocally supported in the literature (Gill, 2003; Kotter, 1995; Beckhard and Harris, 1987). A vision may clarify the direction for change, motivate people to move in that direction and coordinate actions across the organization (Kotter, 1995; Gill, 2003; Hayes, 2018). Moreover, a vision creates a collective sense of what is important (Senge, 1990) and emphasizes what the organization should accomplish rather than modeling a future state. 
TLO

29,3

A clear process to move forward

Several authors have noted the importance of a planned process for moving forward (Beckhard and Harris, 1987; Dannemiller and Jacobs, 1992; Bridges, 2009). Some authors discuss an overarching process for the whole change ahead (Kotter, 1995; Bullock and Batten, 1985). While the order of activities in such processes may vary, recurring themes are exploration (Bullock and Batten, 1985), planning/designing (Taffinder, 1998; Bullock and Batten, 1985; Kotter, 1995), communicating/mobilizing/engaging (Kotter, 1995; Beer, 2009; Gill, 2003), executing/acting (Kotter, 1995) and integrating/learning (Bullock and Batten, 1985; Hayes, 2018). In some change models, the planning and execution are seen as separate, sequential steps (Kotter, 1995; Taffinder, 1998; Bridges, 2009), whereas others see planning and acting as more integrated steps with blurry boundaries (Hayes, 2018). Other authors emphasize the importance of a set of first steps and initiatives that can accelerate progress (Kotter, 1995; Amabile and Kramer, 2011). Some also stress that actions need to be constantly evaluated as the change occurs (Pasmore, 2015).

\section{Dissatisfaction/sense of urgency}

In the change formula (Beckhard and Harris, 1987; Dannemiller and Jacobs, 1992), dissatisfaction with the status quo is necessary. Thus, leaders need to motivate change by creating awareness that something is not right in the organization. Kotter $(1995,2008)$ refers to a sense of urgency, which can be evoked by, for example, leveraging a crisis to break through the complacency or bringing data into the organization from the external environment (Kotter, 2008). This is supported by Conner's (1992) advocacy of pain messages to motivate change, Taffinder's (1998) organizational "awakening," and Lewin's (1947) "emotional stir-up." The sense of urgency must be such that change is the difference between survival and death (Kotter, 1995). The logic is that change requires new behavior, and behavior will change when there is a real understanding of why change is needed (Bridges, 2009; Senge, 1990).

\section{Costs of changelemotional resistance}

Since Lewin's (1947) three-step proposal, one addition to change models has been to include organizational and individual resistance (Rosenbaum et al., 2018). In the change formula (Beckhard and Harris, 1987; Dannemiller and Jacobs, 1992; Cady et al., 2014), resistance is one of the costs of change, particularly when organizational and individual values are threatened (Trader-Leigh, 2002). Lawrence (1969) concludes that people generally do not resist the change as such, but the social, relational change that comes with it. When authors discuss resistance (Thomas and Hardy, 2011; Wadell and Sohal, 1998), and the costs of change (Cady et al., 2014), change is often referred to as something inevitable (Trader-Leigh, 2002). However, Huy (2005) instead proposed positive emotions, such as fun and hope, as drivers for organizational capabilities for renewal, which could be connected to the capabilities required for change (Beer, 2013). Other authors also argue for the need for psychological safety (Edmondson, 2019; Edmondson and Lei, 2014) to learn and innovate.

\section{Contemporary context}

In the 1960s, the average lifespan on the S\&P 500 [1] was 60 years. Today, it is less than 20 years. Scholars discuss the volatile, uncertain, complex and ambiguous (VUCA) context in which organizations exist (Johansen, 2017) and the difficulty of navigating change in such a world (Pasmore, 2015). Many authors conclude that the need for organizational change to remain competitive has increased (Reeves and Deimler, 2011; Satell, 2014), and leaders need to manage a different skillset, for instance conveying purpose (Bonchek, 2013; Fredberg and 
Pregmark, 2018; Pregmark, 2019), positive emotions (Huy, 2005) and creating a space of trust (Edmondson and Lei, 2014; Fredberg and Pregmark, 2021).

In this landscape of unpredictable change (Reeves and Deimler, 2011; Johansen, 2017; Pasmore, 2015), organizations need to respond in new ways (Worley and Mohrman, 2016; Satell, 2014), with a multitude of initiatives (Bartunek and Woodman, 2014), and more emphasis on learning and innovativeness (Worley and Mohrman, 2016; Pregmark, 2019).

Criticism of traditional change models is not new (Tsoukas and Chia, 2002), and there is since long an ongoing discussion whether change is to be seen as planned or emergent (By, 2007). However, the discussion about the applicability of traditional change models - taking an organization from point A to point B has been intensified in academia the recent years. For instance, Worley and Mohrman (2016) writes: "Is there anything more irrelevant and anachronistic than applying change models developed in the 1950s to the development challenges facing organizations today? Despite a world where change, uncertainty, and discontinuity are common, organizations continue to employ traditional change models and emphasize traditional skill sets" (p. 29).

Bartunek and colleagues (Bartunek and Woodman, 2014; Heracleous and Bartunek, 2021) argue for models with more emphasis om temporal dimensions and discusses sequence, timing, pacing, rhythm and polyphony. Worley and Mohrman (2016) suggest a model, where change agents are to engage in four areas: awareness, design, tailoring and monitoring. Pasmore (2015) proposes an iterative process including discovering, deciding, doing and discerning. Fredberg and Pregmark (2021) advocate a combination of trust and pressure to create space for creativity, learning and a continuously updated strategic direction. Research by Huy (2005) focuses on a framework enabling radical change, encompassing learning, mobilization receptivity, retaining key people and promoting organizational creativity. These ideas focus less on change as a process between current and desired state and more on the capabilities to meet a constantly changing environment. Hence, although traditional models to a large extent seem to have their focus on prerequisites for taking an organization from one place to another, models and frameworks mentioned above seem to be more focused on creating a constant readiness for responding to a changing environment. Still, the fast-changing world (Johansen, 2017; Satell, 2014; Pasmore, 2015), low success rate of change (Jacque Mont et al., 2015) and the fact that traditional models are the preferred choice in practice (Worley and Mohrman, 2016; Rosenbaum et al., 2018) justify an intensified discussion.

\section{Data and method}

In practice, it is a recognized phenomenon that many change models in use are not up to date with today's environment. Nevertheless, these models are still commonly used in organizations (Rosenbaum et al., 2018). To study this phenomenon and investigate how components of traditional models are and can be used, I have conducted a qualitative study, with a collaborative research approach (Coghlan, 2011).

The organizations and leaders have primarily been chosen on the basis that they are all undergoing major change as a response to a rapidly changing environment but also on the basis of my possibility as a researcher to get close, deep and to collaborate with top management. I have allowed myself to take different roles within the empirical setting depending on my access. This fits well with the idea of the engaged scholar (Van de Ven, 2007). Bansal et al. (2018) recognize engaged scholarship as a qualitative genre that contributes valuable insights to the management field. The intertwined relationships between scholars and practice are seen as an advantage, giving meaning to findings by combining scientific and practical knowledge, which I strive to do in this paper. 
TLO

29,3

The empirical insights were gathered through collaborative research (Coghlan, 2011; Argyris and Schön, 1996) and based on data collected 2015-2018 from leaders in five organizations, from different industries but all on a radical change journey. Table 1 briefly outlines the empirical context of this paper. As displayed, the roles varied but could all be seen as collaborative. In for instance Parking Inc., I had a dual role as process facilitator/ consultant (only facilitating the TMT change meetings, not providing content) and researchers whereas I worked together with research colleagues on a long term action research contract with Newsgroup, where the research team actively helped setting up ideas and initiatives together with TMT to test ways to change. Other interactions were briefer, for instance where the CEO of Go Energy shared and discussed his case for change at a twoday research meeting I helped organize (invited participants and set up the format for case sharing).

The range of interactions both in terms of duration and frequency has varied as outlined in the Table 1. This could of course have implications for the data analysis where I have more in-depth knowledge and understanding of some of the organizations. However, because I do not aim to compare and contrast the organizations or leaders, but rather pick up common themes, I still believe that it is possible to use the data a one set. Table 2 summarizes the different interactions with organizations.

After each interaction, perceived problems and ideas around change were noted, especially reflections regarding problems and potential with different traditional change factors (Table 3) and later coded and analyzed. The problem identification where mainly done together with the organizations/leaders, but compilation of data and the coding was made by me. The insights were then developed into suggested adaptions of traditional change models. These ideas were tested with leaders for validation and in several parts of the organizations for triangulation (Rothbauer, 2008) as well as with fellow researchers. The coding structure was inspired by Gioia et al. (2012), where quotes around each change factor are summarized into dimensions, leading to themes that were used as basis for suggested implications.

To summarize, the study was designed to highlight potential problems with traditional models and change factors in a contemporary context, where the need for change goes beyond incremental improvements, where the need for polyphony (Bartunek and Woodman, 2014) and innovative activity is important to succeed (Fredberg and Pregmark, 2018). I found such context in five Nordic organizations. Nordic management and organizations are often described as flatter (Hofstede, 1980) when it comes to both power distance and structure. This could have helped me in finding suitable organizations. The research builds on participation in conversations and activities as action researcher, process consultant and/ or case sharing sessions. The interactions ranged from long-term collaboration as a consultant and/or action researcher to shorter interactions of two-day workshops. The priority was to get close to leaders as they worked with change issues because this is key for the collaborative approaches (Coghlan, 2011) which often are said to be useful when trying to understand a phenomenon in depth (Pettigrew et al., 2001; Beer, 2011).

\section{Findings}

In this section, I will outline findings according to the four change factors often represented in traditional models as outlined in the theory section - and just as in the theory section the structure is based on the components in the Gleicher change formula. However, in this section the components will be related to the data indicating both problems and potential with this in a contemporary change context. 


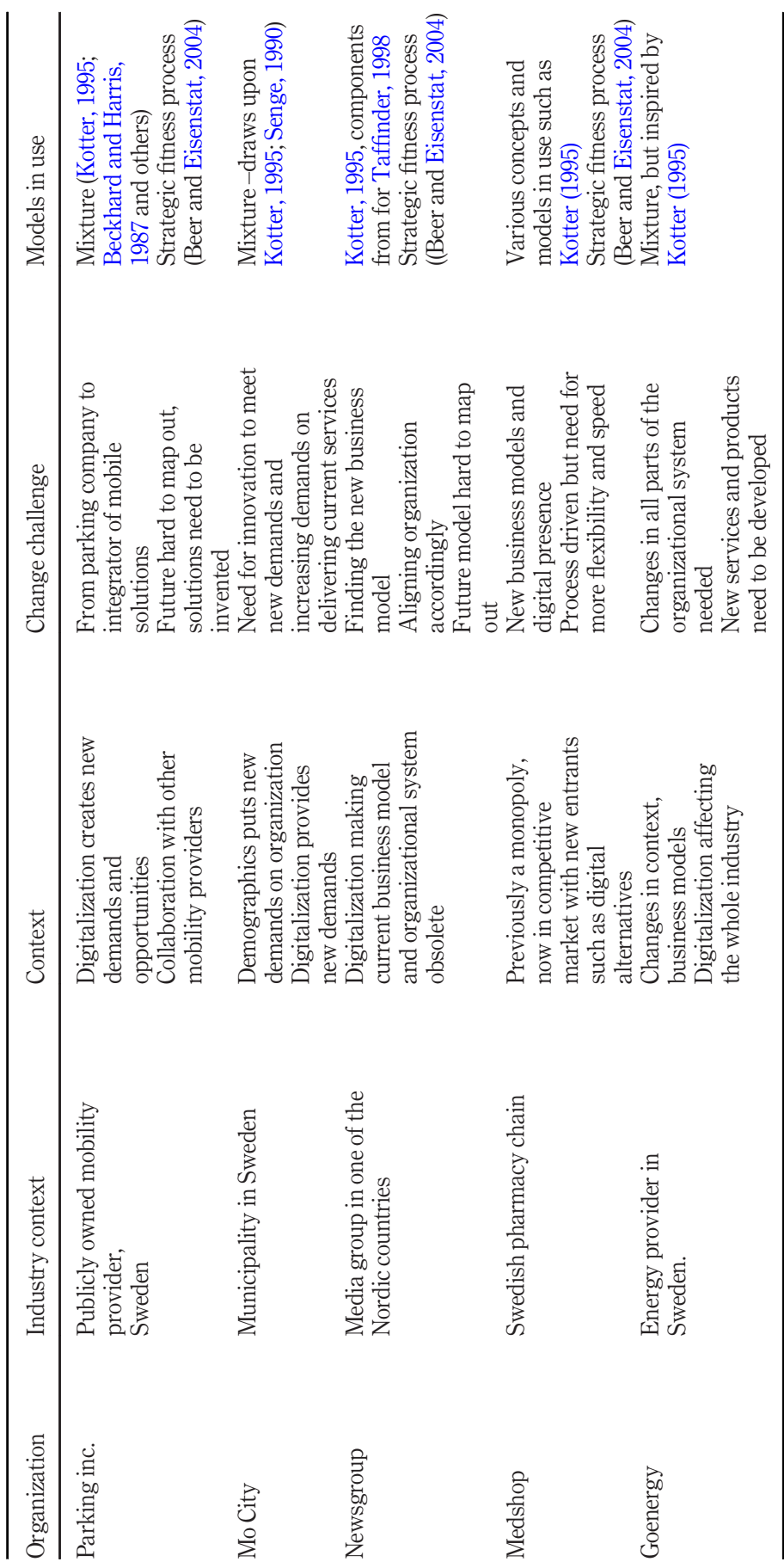

Renewing

models for change

261

Table 1.

Investigated organization, change context and models in use 
TLO
29,3

262

Table 2.

Investigated

organization, nature

of interaction and actors

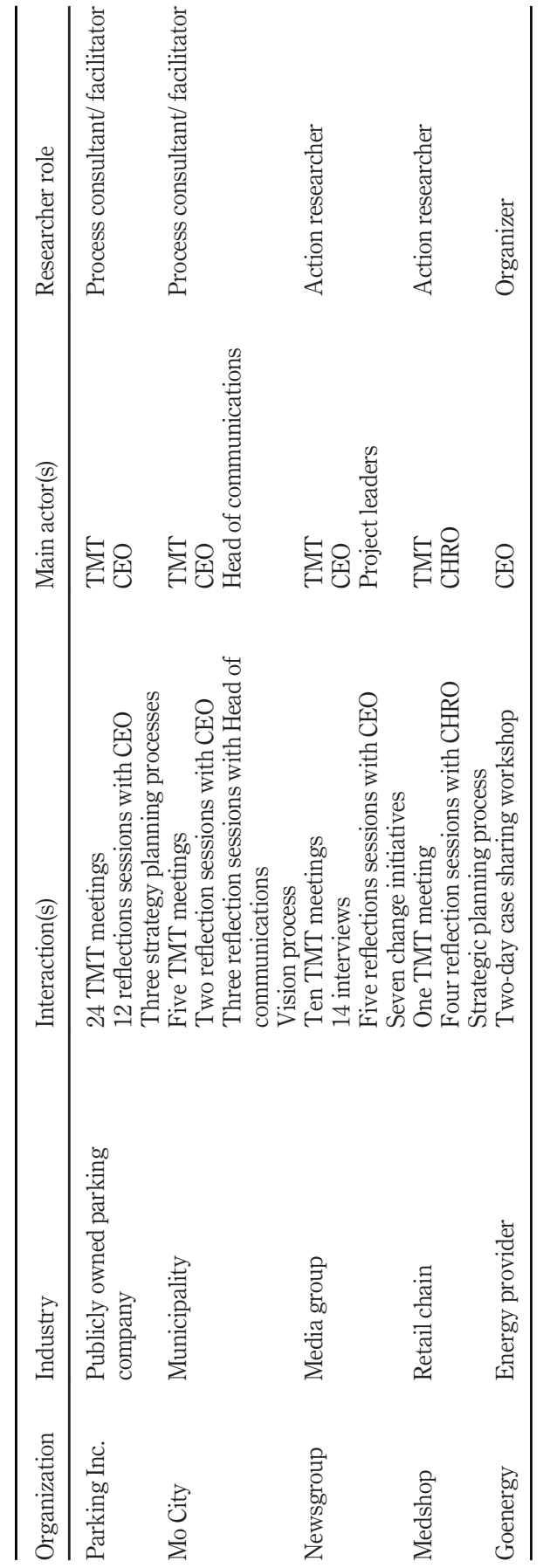




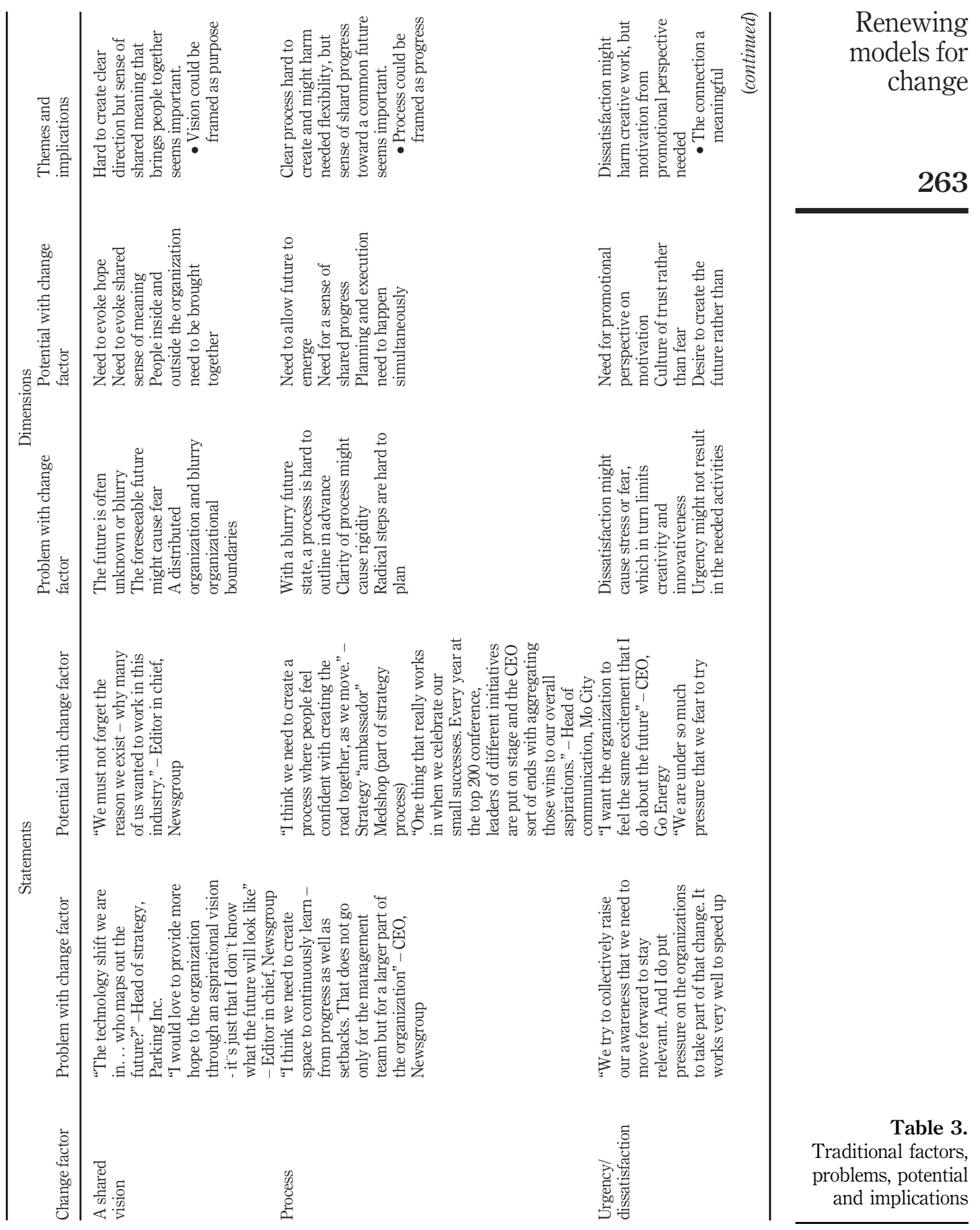




\section{TLO \\ 29,3}

264

Table 3.

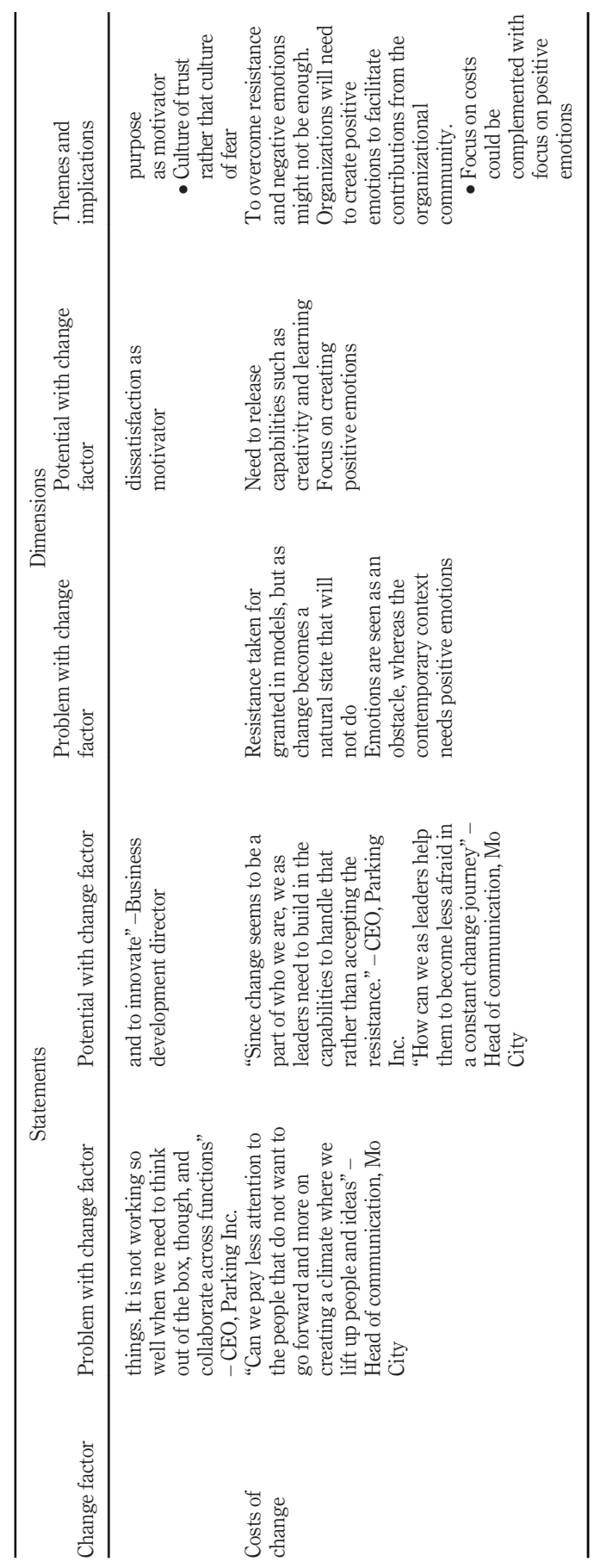




\section{Problems and potential with traditional models}

The organizations in this study were all striving to change in a fast-moving context, using change models in different ways. Some organizations followed the models explicitly to map the change agenda; others used one or two models as inspiration and guidance. It became clear that representatives from the organizations found difficulties related to the applicability of the factors in a contemporary context. However, the data also suggests that at least parts of what the factors represent could be even more important in a contemporary world.

\section{Delivering a strong vision in a contemporary context}

The CEO of Parking Inc. reflected upon her journey as follows:

How could I paint a picture of the future state of our organization? The things we are doing today [...] I couldn"t even have imagined that a few years ago. When someone asks me for expected numbers of parking spaces, coverage, and revenues the coming years, sure I can give them that. But really, I am not even sure that we are going to park cars in the same way[... .] Already, our main product is probably the app and the customer data rather than the parking space. Who would have thought that?

All leaders stated that they considered it part of their job - expected from both board and organization - to deliver a clear future model (ranging from a five year to a 30-year vision) and describe a lack of ability to do so, primarily because of uncertainty in the business environment and fast technology development. The leaders stress the need to unite the organization through a meaningful vision. However, some find it difficult to do so in turbulent times. As put by the editor-in-chief at Newsgroup:

I would love to provide more hope to the organization through an aspirational vision - it"s just that I don"t know what the future will look like. Thus, if a strong vision is seen as a clear framing of a future configuration/destination/model - leaders in this study see it as a difficult factor to deliver upon.

\section{Creating a clear process in a contemporary context}

The CEO of Parking Inc. notes the difficulties of creating a clear process:

Looking back, if I or my top team would have planned for the journey and outlined every step we would never have ended up where we are today. Still, we wanted to create the sense that we were on a journey together. That was a tricky solve for us. How could we in the TMT invite our employees to a journey without showing them the way?

Several organizations discussed the need for clear, yet flexible, processes for change. As noted by Medshop:

We don"t necessarily need a ready-built road to the future - but we need a road to walk on while discovering it.' Similarly, as suggested by the CEO of Newsgroup, a continuous space for learning and display of progress should be created: 'That might not be displaying a road ahead but shows that we are on our way to the future.'

This shows that leaders in this study do not dispute the need for the organization to be on the same track in the change process - but do see difficulties if a clear process is interpreted as creating a clear, step-wise roadmap.

Leveraging sense of urgency in a contemporary context

The business development director of Newsgroup reflects:

Renewing models for change 
It is like the whole organization is running around doing things, but I am not sure we are focusing on the right things, the things that will create our future.' A sales manager in the same organization describes: 'We are told that there is a crisis all the time. We need to sell more, we get it. But we are so afraid of not succeeding so we don"t dare to try something new.

The example above shows the pressure that Newsgroup was under. The willingness to perform and the urgency to succeed were obvious, but they seemed unable to coordinate their efforts toward the future. Other organizations tell similar stories. While they did not seem to have a problem creating a "sense of urgency" or "dissatisfaction," they did have problems leveraging that sense of urgency to mobilize energy and ideas for the future. For example, the CEO of Parking Inc. reflects:

We try to collectively raise our awareness that we need to move forward to stay relevant. And I do put pressure on the organizations to take part of that change. It works very well to speed up things. It is not working so well when we need to think out of the box, though and collaborate across functions.

This data could indicate that urgency and dissatisfaction as a change component is not enough in this fast-paced environment.

\section{Accepting resistance in a contemporary context}

All investigated organizations see indications of resistance. However, leaders in Parking Inc and Mo City discuss the need to refrain from seeing resistance as a "normal" state to be overcome. As expressed by the CEO of Parking Inc.:

Since change seems to be a part of who we are, we as leaders need to build in the capabilities to handle that rather than accepting the resistance.' The head of communication at Mo City noted that people have a right to their emotions but asks: 'How can we as leaders help them to become less afraid in a constant change journey?

Potentially, data here indicates that traditional models puts a too one-sided focus on managing negative emotions rather than on creating the emotional capabilities to move forward.

Data points toward challenges with applying the elements included in traditional change models. However, the need for an overarching frame for renewal processes is evident. As put by the CEO of GoEnergy, "I realize the model we are using is not really working. But I need, and the organization needs, a way of displaying our journey." Support for the different factors in the traditional models is also expressed. The vision is seen as important to unite people, while the process is important for clarity. Some leaders state that a "wake-up call" is necessary, perhaps related to dissatisfaction with the traditional models. The need to manage resistance is also seen as necessary.

\section{Findings on change factors organized}

Table 3 summarize the findings and propose how the traditional change factors can be tweaked or adapted to fit in a contemporary environment. With these tweaks, potentially, traditional models can be more applicable in a contemporary context. The applicability of these tweaks will need further research.

\section{Discussion}

This section will first discuss the findings on each change factor, again with a structure following the logic of the change formula. Thereafter, I will move into propositions of an emerging new(er) change formula. 
Need for a vision when the future is unknown: The data point to a major problem with the change prerequisite of a clear and strong vision: How can top management deliver a clear vision or model of a future state when whole industries are in transition? This problem was already noted in the 1990s by scholars such as Christensen (1997) and has been accentuated through the increasing speed and magnitude of change (Reeves and Deimler, 2011; Johansen, 2017). Still, many models for change advocate the need for a vision of a future state in a change process (Kotter, 1995; Hayes, 2018; Gill, 2003). Even authors stressing a bottom-up approach (Beer, 2009) argue that the overall vision must be clear and originate from management. As described by the CEO of Parking Inc., this can be problematic. In a transition, it is common that no incumbent has a clear view of what the future configuration will look like (Fredberg and Pregmark, 2016). Therefore, it is difficult to respond to the need for a traditional vision, which points to a destination where the future is significantly different, as suggested by previous research (Gill, 2003; Beckhard and Harris, 1987; Kotter; 1995). Because providing the organization with a clear future vision is simply not possible, it could be argued that leaders must find ways to let the future emerge.

Simultaneously, several leaders in this study note the need for something meaningful that directs the organization's activities and for the need to evoke hope. This could be tied to the need for a shared sense of meaning or joint purpose (Adler et al., 2011; Bonchek, 2013). This could potentially be especially relevant in this Nordic setting, where members of the organization often expect to participate both emotionally and practically in the strategic activities. It could, therefore, be argued that more emphasis should be placed on what the organization is created to accomplish than on outlining a clear model of a future state. Hence, though a clear destination or model of a future state seems hard to detail, data in this study indicates that the future needs to emerge - but with a shared direction and meaning.

\section{A clear process that needs to be emergent}

The predictability of change has been discussed in literature for decades (Pasmore, 2015; Mintzberg and Westley, 1992). Following the increasing difficulty with modeling the future, it is arguably even more problematic to define the clear process that is suggested in many change models (Kotter, 1995; Beckhard and Harris, 1987; Cady et al., 2014). Not only is it difficult for leaders to devise a clear process when the future configuration of an organization is unknown, clear steps can potentially harm flexibility (Fredberg and Pregmark, 2018), a nimble way of adapting (Ancona et al., 2019) as well as a needed capability to continuously update the strategic direction (Pregmark, 2019). Leaders quoted in this paper also note that they rely on initiatives of many origins to create the change ahead. This is consistent with proposals calling for a polyphonic approach (Bartunek and Woodman, 2014) but against the idea of an overarching top-down process.

The fundamental idea of emphasizing a clear process (Armenakis and Bedeian, 1999) as key for successful change in traditional change models could still be valid in a contemporary context. With faster changes and more radical leaps (Reeves and Deimler, 2011), organizations are constantly unstable. Many leaders described the need to present an overview of their journey to provide the organization with clarity. Previous studies have discussed ways to provide stability and clarity while allowing flexibility (Fredberg and Pregmark, 2016) and strengthening organizational learning (Senge, 1990; Edmondson, 2019). Moreover, learning has also been said to be a way of change proofing an organization (Drew and Smith, 1995). This study suggests that leaders seemed to have managed to augment recently developed ideas around learning in a bottom-up way (Edmondson, 2019; Worley and Mohrman, 2016; Pregmark, 2019) to the traditional way of thinking about 
TLO

29,3

process as a top down assigned, ready built way to the future, with clear steps defined (Beckhard and Harris, 1987). These clear signs of bottom-up approaches to create emerging processes could relate to the Nordic characteristics of organizations, with lower powerdistance (Hofstede, 1980; Czarniawska-Joerges and Sevón, 2003) and expectations of high degree of participation. Potentially, this could indicate that what previous research has found to be common patterns and structures of Nordic approaches, could be characteristics that are compatible with capabilities needed in fast-paced world.

\section{Dissatisfaction and urgency without fear}

That pressure results in action is a known phenomenon. The business development director of Newsgroup highlights that they all felt the pressure and sense of urgency but questions if that made them act appropriately or whether pressure and negative emotions spur innovativeness. The argument that dissatisfaction (Beckhard and Harris, 1987; Cady et al., 2014) or urgency (Kotter, 1995, 2008) are necessary for successful change suggests that the organizational community needs a reason to break out of its complacency. It is not as clear, however, that this prerequisite encourages the creation of a new future. In such situations, learning, creativity and collaboration (Beer, 2013; Huy, 2005) are important and these capabilities are not supported by pressure (Amabile and Kramer, 2011) but by trust and psychological safety (Edmondson, 2019).

In this study, leaders do see the value and need to create strong motivation to leave the old behind but argue that they need to do that in a way that uses the creative and innovative potential in the organization - a tricky solve that has been discussed by for instance (Fredberg and Pregmark, 2021). Thus, it seems like the leaders, though using traditional models, intuitively saw the need to infuse modern models and thinking around change, advocating need for creativity (Huy, 2005; Johansen, 2017) and strong emotional engagement toward a shared purpose/direction (Pasmore, 2015; Fredberg and Pregmark, 2018), rather than just motivation to leave status quo.

\section{Emotions as costs or assets}

In many traditional models, emotions take a back seat and are seen as "costs" of change. That is, change indisputably means negative emotions and resistance (Beckhard and Harris, 1987; Cady et al., 2014; Beer, 2007; Wadell and Sohal, 1998). Leaders quoted in this paper argue that they put too much effort into dealing with resistance and should instead focus on encouraging learning, creativity, idea generation and collaboration. Thus, to simply overcome negative emotions will not do. Instead, as argued by some of the leaders in this study, capabilities such as learning (Huy, 2005; Beer, 2013) and creativity (Huy, 2005) need to be supported, perhaps by evoking positive emotions (Johansen, 2017) and creating an environment of emotional safety (Edmondson and Lei, 2014).

Managing change with stronger links to features like trust and positive emotions - as suggested by for instance Huy (2005) or Edmonson (2019), could reduce that sense of "costs," leading to an acceptance of a weaker vision and process. This may be important in a contemporary context, suited for industry transitions, where the vision of the future state is weak.

\section{Emerging new change formula}

The discussion above demonstrates that the traditional change models, though not always effective (Barends et al., 2014), contain fundamental elements for being able to leave the old model of working behind and to successfully move from one state to another. It also demonstrates some paradoxes and problems with employing change factors in a contemporary setting (Reeves and Deimler, 2011), with added complexity (Johansen, 2017) 
and need for multiple initiatives (Pasmore, 2015). In a contemporary context, it is difficult to clearly define the future vision. However, this study shows that a unifying vision is important to mobilize energy and effort and could be interpreted as a collective sense of what is important (Senge, 1990), as shared meaning or purpose (Adler et al., 2011; Bonchek, 2013). Hence, data in this study suggest a focus on a shared purpose rather than a traditional vision. Furthermore, a clear process for the change ahead is difficult to outline in a rapidly changing context. This study confirms problems with outlining a clear process but also shows the need for a shared sense of being on the right (and same) track. Previous research also produce evidence that people can do without a ready-built road to the end station (Fredberg and Pregmark, 2016; Mintzberg and Westley, 1992), Therefore, this paper argues that there should be less focus on a clear process and more emphasis on continuously creating structures that allow progress to be demonstrated and learned from. This corresponds with the need for polyphony (Bartunek and Woodman, 2014), iterative processes (Pasmore, 2015) and nimble ways of working (Ancona et al., 2019).

The magnitude of the change ahead is great in a VUCA world (Johansen, 2017). Logically, the collective sense of urgency would be at least as important as in a more traditional change process. However, in a setting where organizational capabilities such as creativity (Huy, 2005) and learning (Worley and Mohrman, 2016; Edmondson, 2019) are required, this study shows that the urgency needs to be complemented by focus of and future rewards and a safe space for testing and innovating. Thus, the focus should be on creating desire to reach a meaningful purpose and to encourage a culture of trust, rather than focus on dissatisfaction and pressure.

There seems to be a link between positive emotions (Amabile and Kramer, 2011) on the one hand and organizational capabilities such as creativity, learning and receptivity to change (Huy, 2005) on the other hand. Hence, some of the focus that in traditional models is put on managing resistance could be directed towards creating positive emotions. The leaders also pointed to the need to create positive emotions to encourage capabilities to actively engage in the change ahead. Hence, I argue that more emphasis could be put on positive emotions as levers for organizational capabilities to change, which is in line with thinking from Pasmore (2015) and Huy (2005).

Hence, the data collected for this paper recognize that traditional change models reflect organizational needs when managing change and should therefore not be dismissed. The interpretation and application need to be re-defined, however, promoting a shift in focus and temporality. Although traditional models largely reflect a top-down perspective where the aim is to convince the organization to abandon the old, this paper advocates promoting organizational capability to create the future, continuously. The old - but still commonly applied - change formula (vision*process*dissatisfaction $>$ costs of change) could be complemented by new formula: Purpose*progress*trust $>$ (costs - positive emotions). This new formula could indicate the need for a shift toward a more inclusive and emerging change effort on the left side and the need for balancing focus on resistance/costs with focus on creating positive emotions on the right side.

\section{Contribution}

While a majority of change initiatives fail (Jacquemont et al., 2015), adaptability is said to be the new competitive advantage (Reeves and Deimler, 2011). Any paper attempting to shed light on how organizations can change more effectively should therefore be of interest for both theory and practice. According to the leaders in this paper, organizations need to change in different ways than before. They see a contemporary context putting new demands on their ways of managing and changing their organizations. Still, they admit to 
using traditional models as tools, consistent with claims from Worley and Mohrman (2016). However, in this study it is clear that they are not simply trying to make those models work - they are incorporating thinking and structures that can help them navigate better in a new world - activities with great similarities with recent thinking from academia (Bartunek and Woodman, 2014; Edmondson, 2019; Pasmore, 2015; Fredberg and Pregmark, 2021). Thus, this paper contributes to theory through linking traditional and newer models for change. Moreover, this paper indicates that features often related to Nordic management tradition could support a transition toward more modern models for change, adapted to a fast-paced, VUCA world.

This paper argues that it may not be the right call from academia to ask leaders to completely abandon the tools they know. In the transition we are in, it is perhaps to be expected that there is a gap between the very front end of theory and the reality of practice. This paper contributes to practice through proposing an actionable framework that could serve as an overarching guide but without the outdated planned stepwise process. The discussion in this paper will hopefully help leaders move toward a more contemporary use of change models without disregarding influential work from the past - and start their transition toward newer models that will best support their change journeys. I argue that this is encouraging - to see that leaders in rather traditional industries are incorporating newer thinking with polyphonic and entrepreneurial approaches (Bartunek and Woodman, 2014; Fredberg and Pregmark, 2018) as well as focus on learning (Edmondson, 2019), creativity (Amabile and Kramer, 2011) and purpose (Bonchek, 2013) in their change processes. To what extent this is because of a Nordic context (Aiginger and Guger; 2006) with flatter organizations (Hofstede, 1980) and where members of an organization often expect to be invited into strategic questions needs further investigation, however.

This proposition of a new formula could be seen as a complement to the older one. It is easy to imagine several situations, where the older formula is still valid - for instance in stable contexts or in situations where organizations or parts of organizations need to execute quickly on predefined goals and targets. The new change formula proposition is suitable for a context where the future is unknown, and the organization needs to create the future rather than execute on plans. Potentially, both the formulas can be in play at the same time in the same organization. The challenge for leaders and organizations in that case would be to identify the context and chose the right formula for the occasion.

Thus, I hope that this paper could help leaders of change to ask themselves if they are on a journey that cannot easily be defined by top management as an "A to B" process. If the answer is (partly) yes, my hope is that this paper can support those leaders" thinking with a framework that is more tailored for bottom-up approaches where the future configuration needs to be co-created. In addition, I see potential for organizations in a Nordic setting to further test if they are using its special features (such as low power distance and flat organizations) to create advantages in a fast moving, VUCA world. Potentially, this paper and the suggested change formula could be of support in that effort.

\section{Limitations}

This study is based in a Nordic context. Though this is addressed in this paper, it is possible that this fact has influenced the results. It is possible that the blend of older and newer models I see in the data at least partly has its explanation in the characteristics often found in the Nordic management tradition. This could open up for further research - and potentially study if the organizations rooted in the Nordic management tradition are particularly well equipped to adapt to newer thinking around change. 
Further, as always with collaborative approaches, the researcher influences the context. It is hard to determine to what extent this has influenced the results. The nature of the also interactions with the different organizations varies, which potentially influences the result. However, the data, emerging categories and the final conclusions and contributions have been tested with leaders as well as with colleagues for mitigating the risks mentioned above.

It is my hope that this paper can spark ideas for further research as well as for practice to test these propositions of a complementing formula for change.

\section{Note}

1. The Standard and Poor's 500 is a stock market index that tracks 500 large companies listed on stock exchanges in the USA.

\section{References}

Adler, P., Heckscher, C. and Prusak, L. (2011), "Building a collaborative enterprise”, Harvard Business Review, July-August, available at: https://hbr.org/2011/07/building-a-collaborative-enterprise

Aiginger, K. and Guger, A. (2006), "The ability to adapt: why it differs between the scandinavian and continental european models", Intereconomics, Vol. 41 No. 1, pp. 14-23.

Amabile, T. and Kramer, S. (2011), “The progress principle: using small wins to ignite joy, engagement, and creativity at work", Harvard Business Review Press.

Ancona, D., Backman, E. and Isaacs, K. (2019), "Nimble leadership, walking the line between creativity and chaos", Harvard Business Review, (July-August 2019), Nimble Leadership (hbr.org).

Argyris, C. and Schön, D. (1996), Organizational Learning II: Theory, Method, and Practice, Addison Wesley, Reading, MA.

Armenakis, A.A. and Bedeian, A.G. (1999), "Organizational change: a review of theory and research in the 1990s", Journal of Management, Vol. 25 No. 3, pp. 293-315.

Bansal, P., Smith, W.K. and Vaara, E. (2018), "New ways of seeing through qualitative research", Academy of Management Journal, Vol. 61 No. 4, pp. 1189-1195.

Barends, E.G.R., Janssen, B., Have, W. and ten Have, S. (2014), "Effects of change interventions: what kind of evidence do we really have"? The Journal of Applied Behavioral Science, Vol. 50 No. 1, pp. 5-27.

Bartunek, J. and Woodman, R.W. (2014), "Beyond lewin: toward a temporal approximation of organization development and change", Annual Review of Organizational Psychology and Organizational Behavior, Vol. 2 No. 1, pp. 157-182.

Beckhard, R. and Harris, R.T. (1987), Organizational Transitions: Managing Complex Change, (2nd ed.), Reading, MA: Addison-Wesley.

Beer, M. (2007), "Leading change”, Harvard Business School Background Note 488-037, January 1988, (Revised January 2007).

Beer, M. (2009), High Commitment High Performance: How to Build a Resilient Organization for Sustained Advantage, John Wiley and Sons Inc.

Beer, M. (2011), "Making a difference and contributing useful knowledge: principles derived from life as a Scholar-Practitioner", in Mohrman, S.A. and . Lawler, E.E (Eds), Useful Research: Advancing Theory and Practice, Berrett-Koehler.

Beer, M. (2013), "The strategic fitness process: a collaborative action research method for developing and understanding organizational prototypes and dynamic capabilities", Journal of Organization Design, Vol. 2 No. 1, pp. 27-33.

Beer, M. and Eisenstat, R.A. (2004), "How to have an honest conversation about your business strategy", Harvard Business Review, Vol. 82 No. 2, pp. 82-89. 
Bonchek, M. (2013), "Purpose is good. Shared purpose is better", Harvard Business Review, March 14, available at: https://hbr.org/2013/03/purpose-is-good-shared-purpose

Bridges, W. (2009), Managing Transitions: Making the Most of Change, (3rd ed.), Da Capo Press.

Bullock, R.J. and Batten, D. (1985), "It's just a phase we're going through': a review and synthesis of OD phase analysis", Group and Organization Studies, Vol. 10 No. 4, pp. 383-412.

Bushe, G.R. and Marshak, R.J. (2009), "Revisioning organization development: diagnostic and dialogic premises and patterns of practice", The Journal of Applied Behavioral Science, Vol. 45 No. 3, pp. 348-368.

Cady, S.H., Jacobs, R., Koller, R. and Spalding, J. (2014), “The change formula: myth, legend, or lore?”, OD Practitioner, Vol. 46 No. 3, pp. 32-39.

Christensen, C.M. (1997), The Innovators Dilemma: When New Technologies Cause Great Firms to Fail, Cambridge, MA: Harvard Business School Press.

Coghlan, D. (2011), "Action research: exploring perspectives on a philosophy of practical knowing", Academy of Management Annals, Vol. 5 No. 1, pp. 53-87.

Conner, D. (1992), Managing at the Speed of Change, New York, NY: Random House.

Czarniawska-Joerges, B. and Sevón, G. (2003), The Northern Lights: Organization Theory in Scandinavia, Liber.

Dannemiller, K.D. and Jacobs, R.W. (1992), "Changing the way organizations change: a revolution of common sense", The Journal of Applied Behavioral Science, Vol. 28 No. 4, pp. 480-498.

Drew, S.A.W. and Smith, P.A.C. (1995), "The learning organization: 'change proofing' and strategy", The Learning Organization, Vol. 2 No. 1, pp. 4-14.

Edmondson, A. (2019), "The fearless organization: creating psychological safety in the workplace, for learning, innovation, and growth", ISBN-13: 978-1119477242.

Edmondson, A. and Lei, Z. (2014), "Psychological safety: the history, renaissance, and future of an interpersonal construct", Annual Review of Organizational Psychology and Organizational Behavior, Vol. 1 No. 1, pp. 23-43.

Fredberg, T. and Pregmark, J. (2016), "Transformation in a tightly nested system: employing fast cycles of change", in Noumair, D.A. and (Rami) Shani, A.B. (Eds), Research on Organization Change and Development, Emerald Group Publishing Limited, Bingley, Vol. 24, pp. 185-219.

Fredberg, T. and Pregmark, J.E. (2018), "Organization renewal through corporate entrepreneurship: When the seed changes the soil", in Noumair, D.A. and (Rami) Shani, A.B. (Eds), Research on Organization Change and Development, Emerald, Bingley, Vol. 26.

Fredberg, T. and Pregmark, J.E. (2021), "Organizational transformation: handling the double-edged sword of urgency”, Long Range Planning, p. 102091, doi: 10.1016/j.lrp.2021.102091.

Gill, R. (2003), "Change management or change leadership?", Journal of Change Management, Vol. 3 No. 4, pp. 307-318.

Gioia, D.A., Corley, K.G. and Hamilton, A.L. (2012), "Seeking qualitative rigor in inductive research: notes on the Gioia methodology", Organizational Research Methods, Vol. 16 No. 1, pp. 15-31.

Hayes, J. (2018), The Theory and Practice of Change Management, (5th ed.), Palgrave, McMillan.

Heracleous, L. and Bartunek, J. (2021), "Organization change failure, deep structures and temporality: appreciating wonderland", Human Relations, Vol. 74 No. 2, pp. 208-233, doi: 10.1177/ 0018726720905361.

Hofstede, G. (1980), "Culture and organizations", International Studies of Management and Organization, Vol. 10 No. 4, pp. 15-41.

Huy, N.Q. (2005), “An emotion-based view of strategic renewal”, in Szulanski, G., Porac, J. and Doz, Y., (Eds), Strategy Process (Advances in Strategic Management), Emerald, Bingley, Vol. 22, pp. 3-27. 
Jacquemont, D., Maor, D. and Reich, A. (2015), "How to beat the transformation odds", McKinsey survey, April, available at: www.mckinsey.com/business-functions/organization/our-insights/ how-to-beat-the-transformation-odds (accessed 14 January 2019).

Johansen, B. (2017), The New Leadership Literacies: Thriving in a Future of Extreme Disruption and Distributed Everything, Berrett-Koehler.

Kotter, J.P. (1995), "Leading change", Harvard Business Review, March-April, available at: https:// eoeleadership.hee.nhs.uk/sites/default/files/leading_change_why_transformation_efforts_fail.pdf

Kotter, J.P. (2008), A Sense of Urgency, Harvard Business School Publishing.

Lawrence, P.R. (1969), "How to deal with resistance to change", Harvard Business Review, January, 1969, available at: https://hbr.org/1969/01/how-to-deal-with-resistance-to-change

Lee, M.Y. and Edmondson, A.C. (2017), "Self-managing organizations: exploring the limits of lesshierarchical organizing”, Research in Organizational Behavior, Vol. 37, pp. 35-58, doi: 10.1016/j. riob.2017.10.002.

Lewin, K. (1947), "Frontiers in group dynamics: concept, method and reality in social science: Social equilibria and social change", Human Relations, Vol. 1 No. 1, pp. 5-41.

Mintzberg, H. and Westley, F. (1992), "Cycles of organizational change”, Strategic Management Journal, Vol. 13 No. S2, pp. 39-59.

Ortenblad, A. (2002), “A typology of the idea of learning organization”, Management Learning, Vol. 33 No. 2, pp. 213-230.

Pasmore, W.A. (2015), Leading Continuous Change: Navigating Churn in the Real World, BerrettKoehler.

Pettigrew, A.M., Woodman, R.W. and Cameron, K.S. (2001), "Studying organizational change and development: challenges for future research", Academy of Management Journal, Vol. 44 No. 4, pp. 697-713.

Pregmark, J.E. (2019), Mastering Change through Innovative Initiatives: Contextual Ambidexterity as a Process, Gothenburg: Chalmers University of Technology.

Reeves, M. and Deimler, M. (2011), "Adaptability: the new competitive advantage”, Harvard Business Review, July-August, 2011, available at: https://hbr.org/2011/07/adaptability-the-newcompetitive-advantage

Rosenbaum, D., More, E. and Steane, P. (2018), "Planned organisational change management: forward to the past?An exploratory literature review", Journal of Organizational Change Management, Vol. 31 No. 2, pp. 286-303.

Rothbauer, P. (2008), “Triangulation”, in L. Given (Ed.), The SAGE Encyclopedia of Qualitative Research Methods, Sage, (pp. 892-894).

Satell, G. (2014), “The only viable strategy is adaptation”, Harvard Business Review, available at: https://hbr.org/2014/06/the-only-viable-strategy-is-adaptation (accessed 25 June 2014).

Senge, P. (1990), The Fifth Discipline: The Art and Practice of the Learning Organization, New York, NY: Doubleday.

Taffinder, P. (1998), Big Change: A Route-Map for Corporate Transformation, New York, NY: John Wiley.

Thomas, R. and Hardy, C. (2011), "Reframing resistance to organizational change", Scandinavian Journal of Management, Vol. 27 No. 3, pp. 322-331.

Trader-Leigh, K.E. (2002), "Case study: identifying resistance in managing change", Journal of Organizational Change Management, Vol. 15 No. 2, pp. 138-155.

Tsoukas, H. and Chia, R. (2002), "On organizational becoming: rethinking organizational change", Organization Science, Vol. 13 No. 5, pp. 567-582.

Van de Ven, A.H. (2007), Engaged Scholarship: A Guide for Organizational and Social Research, New York, NY: Oxford University Press. 
TLO

29,3

Wadell, D. and Sohal, A.S. (1998), "Resistance: a constructive tool for change management", Management Decision, Vol. 36/ No. 8, pp. 543-548.

Winby, S. and Worley, C.G. (2014), "Management processes for agility, speed, and innovation", Organizational Dynamics, Vol. 43 No. 3, pp. 225-234.

Worley, C. and Mohrman, S. (2016), "A new view of organization development and change competencies: the engage and learn model", in Jamieson, D.W., Barnett, R-C. and Buono, A.F. (Eds), Consultation for Organizational Change Revisited, Charlotte, NC: Information Age Publishing, pp. 29-48.

\section{Corresponding author}

Johanna E.Pregmark can be contacted at: pregmark@chalmers.se

For instructions on how to order reprints of this article, please visit our website: www.emeraldgrouppublishing.com/licensing/reprints.htm

Or contact us for further details: permissions@emeraldinsight.com 